\title{
Promoção de habilidades cognitivas e educação: um modelo de análise de programas de desenvolvimento cognitivo
}

\author{
Teresa N. R. Gonçalves \\ UIED/FCT/Universidade Nova de Lisboa
}

\section{Introdução}

A tarefa educativa é sustentada por um conjunto de aparatos conceptuais que enquadram a reflexão e a prática pedagógica nas suas distintas vertentes e dimensões. Desde há largas décadas que o corpus teórico de referência relativo aos sistemas educativos ocidentais tem sido influenciado principalmente pelos contributos da psicologia cognitiva e do desenvolvimento (Piaget, Vygotsky, Bruner) e das chamadas teorias progressistas da educação (Dewey). Estas têmse constituído como marcos teóricos de referência, a partir dos quais têm sido pensados e organizados os modelos e as práticas educativas vigentes; deles emergiu progressivamente a concepção dominante do sujeito a educar e das prioridades e orientações formativas a definir, defender e estabelecer.

Contudo, e apesar das críticas frequentes aos sistemas educativos actuais e das dúvidas relativas ao seu sucesso na formação de cidadãos preparados para responder aos desafios e às necessidades das rápidas transformações que atravessam as nossas sociedades, juntamente com os discursos recorrentes sobre a chamada crise da educação, as bases teóricas que lhes subjazem raramente têm sido questionadas, amplamente debatidas ou consideradas em toda a sua extensão, tendo em conta todas as suas implicações, o que tem originado interpretações contraditórias e ambíguas e fomentado propostas pedagógicas que se considera serem problemáticas e questionáveis: quer do ponto de vista dos resultados alcançados, como do tipo de intervenção que propõem ou ainda na forma como entendem o sujeito a educar, o desenvolvimento e funcionamento cognitivo e as capacidades valorizadas e promovidas.

O âmbito da educabilidade cognitiva ou intervenção cognitiva não tem sido excepção, na medida em que tem constituído um campo privilegiado de experimentação e aplicação explícita de modelos da cognição originados por essas teorias e materializados em programas que procuram explicitamente promover as capacidades cognitivas dos sujeitos, para além dos conteúdos curriculares tradicionais. Nessa medida, modelos como o do processamento da informação, emergente da psicologia cognitiva, ou o do desenvolvimento psicológico, de Piaget, ou ainda o modelo 
sócio-histórico, de Vigotsky, no campo da psicologia do desenvolvimento, têm servido de base para a criação de propostas de intervenção cognitiva de distinta índole e com diferente alcance que se vêm disseminando desde meados do século passado até a actualidade em vários países e em diversos contextos educativos.

No entanto, os seus resultados e a forma de aplicação, longe de serem consensuais ou claramente animadores, têm levantado algumas questões importantes, principalmente no que diz respeito a tentativas de implementação massiva de algumas dessas propostas (Fernándes Ballesteros et al., 1984) ou mesmo relativamente à avaliação dos seus resultados. ${ }^{1}$ Curiosamente, as teorias que lhes subjazem não têm sido objecto de questionamento explícito nem submetidas a uma análise crítica mais profunda. Normalmente, as dificuldades na avaliação ou o fracasso de algumas experiências de aplicação dos programas são atribuídos ou a uma incorrecta aplicação por parte dos professores/aplicadores, ou à ausência de instrumentos fiáveis para a avaliação, mas raramente às teorias que servem de referência à construção dos programas (Nickerson, Perkins e Smith, 1985; Yuste Hernanz, 1997). O presente estudo parte dessa constatação para aprofundar nas causas dessa situação e avançar hipóteses em relação a uma resposta e explicação.

A presente proposta de modelo de análise de Programas de Desenvolvimento Cognitivo (PDC) toma como referência a teoria da complexidade (Morin, 1992) e baseia-se nos constructos sujeito multidimen-

${ }^{1}$ Relativamente à avaliação dos programas, ver Perraudeau (1996), Hamers e Overtoom (1998), Nickerson, Perkins e Smith (1985). Huteau e Loarer (1992) enumeram algumas dificuldades relativas à avaliação de programas: a inexistência de um modelo teórico único da inteligência; a dificuldade da avaliação da transferência; a dificuldade em avaliar a estabilidade temporal dos efeitos dos programas; a dificuldade em definir e considerar as variáveis de personalidade e do domínio afectivo-emocional; a necessidade de ter em conta factores relacionados com a adaptação escolar e profissional; a necessidade de tomar em consideração as variáveis moderadoras que intervêm na intensidade dos efeitos produzidos pelos programas. sional e plasticidade neuronal. Situa-se, por isso, no contexto do debate sobre a educabilidade cognitiva, assim como no âmbito das teorias mais recentes sobre o funcionamento e a evolução dos sistemas vivos e do funcionamento e desenvolvimento do cérebro. Entende-se que as teorias emergentes no âmbito das ciências cognitivas oferecem uma perspectiva da cognição e do desenvolvimento cognitivo alternativa às teorias vigentes, tanto no âmbito educativo em geral como no âmbito da intervenção cognitiva. Permitem uma nova concepção do sujeito da educação, mais complexa e, ao mesmo tempo, mais integradora e compreensiva em relação à sua diversidade e multidimensionalidade e exigem, consequentemente, novas formas de pensar e promover o seu desenvolvimento. O modelo de análise proposto pretende contribuir para pensar as propostas existentes em relação às teorias emergentes, a partir de uma perspectiva crítica e seguindo uma orientação interpretativa-qualitativa que permita analisar e comparar alguns programas segundo as novas perspectivas sobre o sujeito. Parte-se, por isso, da convicção da necessidade de uma aproximação sistémica e aberta ao estudo da cognição e do desenvolvimento cognitivo, entendido este último como um fenómeno complexo e multidimensional, que permita integrar os conhecimentos, investigações e reflexões sobre a cognição e a sua promoção numa teoria mais compreensiva dos fenómenos relacionados a ela.

O modelo de análise que se propõe parte do questionamento dos modelos teóricos que estão na base dos PDC. Propõe como referenciais teóricos da análise empreendida as teorias do desenvolvimento e da cognição emergentes das neurociências cognitivas e da biologia evolutiva, integradas dentro do paradigma da complexidade $^{2}$ (Morin, 1992; Jörg, Davis e Nickmans, 2007) e en-

${ }^{2}$ A teoria da complexidade oferece um horizonte teórico e metodológico a partir do qual as reflexões sobre o desenvolvimento e a cognição podem ser reequacionadas dentro de um horizonte mais vasto de relações e numa perspectiva integradora. Essa teoria reconhece a complexidade dos processos de mudança e as relações entre diferentes níveis e dimensões de um mesmo fenómeno. Permite, por isso, expressar a emergência de novas formas de auto- 
tendidas no âmbito de uma "pedagogia da possibilidade"3 (Bernal \& Gonçalves, 2008), e elabora a partir delas um modelo de análise a aplicar a um conjunto de programas seleccionados. Considera-se que o referido paradigma entendido como um conjunto de assumpções básicas e ferramentas conceptuais que dominam os pensamentos, discursos e teorias -, juntamente com as teorias emergentes sobre o funcionamento e desenvolvimento cognitivo, desafiam as ciências da educação a reconsiderar as teorias dominantes da cognição e da aprendizagem e a questionar certas perspectivas desenvolvimentalistas mais tradicionais, podendo, por isso, servir de base para uma análise conceptual dos programas em causa.

As questões da investigação centraram-se nos seguintes aspectos ou dimensões dos programas: os seus pressupostos teóricos, o seu papel no desenvolvimento das habilidades cognitivas, a sua relação com a realidade escolar e as questões ou os problemas relacionados com a sua avaliação. Duas constatações iniciais foram de crucial importância: o facto de que a questão do sujeito da educação raramente é suscitada ou explicitamente analisada nas distintas propostas ou mesmo nos estudos existentes sobre os PDC, assim como o facto de que as implicações das teorias subjacentes aos programas raramente são questionadas ou amplamente consideradas pelos autores dos programas.

Para empreender a construção do modelo de análise partiu-se dos seguintes princípios:

- As formulações teóricas, metodológicas e técnicas dos PDC podem ser analisadas em si mesmas e comparadas;

organização em toda a sua complexidade e globalidade (Bunge, 2004; Morin, 1992; Capra, 1998).

${ }^{3}$ A pedagogia da possibilidade assenta na ideia de que o sujeito é um sistema integrado, dinâmico e não fechado. É, na sua multidimensionalidade, complexidade e narratividade, um sujeito de possibilidade. A história do desenvolvimento é que irá determinar que possibilidades se realizarão. O papel da educação seria, nesse sentido, a construção e apresentação de um espaço de possibilidades que permitam a abertura e a concretização dessas possibilidades.
- Essas formulações teóricas e seus conceitos são determinantes para a aplicação dos programas;

- Uma análise conceptual, hermenêutica e filosófica pode ser relevante para melhorar as propostas existentes e para uma reflexão sobre o papel dos PDC, sua função e implementação;

- Existe a necessidade de comparar os programas entre si.

Considerou-se que existem muitas questões em aberto relativamente à educabilidade cognitiva que se entende que, passadas algumas décadas desde o seu surgimento, devem colocar-se e analisar-se relativamente aos dados e conhecimentos disponíveis actualmente. Essa perspectiva pressupõe o questionar e discutir:

a) Alguns dos argumentos utilizados para justificar a necessidade e pertinência da educabilidade cognitiva;

b) A forma como se entende o sujeito da intervenção cognitiva;

c) A definição e utilização de alguns dos conceitos centrais da educabilidade cognitiva;

d) Os referenciais teóricos dos programas;

e) Os problemas relacionados com a sua avaliação e integração no contexto escolar.

Defende-se:

- A necessidade de uma meta-análise dos programas; e

- A necessidade de um novo paradigma de referência da cognição.

Propõe-se:

- Uma nova análise baseada num modelo explícito.

No intuito de enquadrar o modelo de análise, farse-á uma apresentação geral dos PDC, a análise dos 
contributos das ciências cognitivas na definição dos referenciais teóricos que servem de base à construção do modelo de análise, assim como a apresentação do modelo, sua aplicação e resultados alcançados, para finalmente apresentar algumas conclusões emergentes da investigação.

\section{Os programas de desenvolvimento cognitivo}

No âmbito educativo, a promoção do desenvolvimento cognitivo tem-se materializado em distintas propostas de intervenção, conhecidas como programas de "ensinar a pensar" ou programas de desenvolvimento cognitivo (PDC). Os PDC são propostas de intervenção estruturadas cujo objectivo é promover o treino das capacidades cognitivas dos indivíduos, no intuito de evitar erros de raciocínio e de promover uma melhor utilização dos recursos cognitivos. São programas práticos que se constituem como propostas dirigidas explicitamente ao treino de uma grande variedade de capacidades ou habilidades cognitivas. Nessa medida, propõem determinadas metodologias, objectivos e estratégias, têm durações distintas e dirigem-se a públicos diversos. Essas propostas surgiram a partir de meados do século passado e foram-se difundindo e aplicando em diversos contextos educativos, sociais e culturais, continuando actualmente a ser aplicados um pouco por todo o mundo. Na sua base estão modelos de desenvolvimento e funcionamento cognitivo que têm tido ampla influência no campo educativo. $\mathrm{O}$ modelo racionalista, o modelo sócio-histórico e o modelo do processamento da informação têm sido modelos dominantes nesse âmbito (Hamers \& Overtoom, 1998; Perraudeau, 1996; Sorel, 1994), com claro predomínio deste último.

A ausência de análise crítica e de questionamento dos conceitos e teorias relacionados com a cognição e o desenvolvimento cognitivo no âmbito da promoção cognitiva, juntamente com a emergência de novos modelos da cognição e do desenvolvimento em diferentes áreas do saber, indiciam a necessidade de uma aproximação crítica ao enquadramento conceptual e design dos referidos programas.
$\mathrm{Na}$ investigação em torno da intervenção cognitiva distingue-se, geralmente, entre programas de âmbito geral, isto é, programas que procuram promover o desenvolvimento de capacidades gerais de pensamento (por exemplo: o pensamento criativo, o raciocínio crítico), e programas de âmbito específico, ou seja, que trabalham capacidades específicas (por exemplo: o pensamento científico, as estratégias de leitura e compreensão). A sua estrutura difere dependendo dos contextos, objectivos da intervenção e da sua relação com o currículo escolar. No que se refere a este último aspecto, existem programas que se integram em uma ou mais disciplinas do currículo e outros que se constituem como momentos "à parte", criando um espaço próprio para o ensino do pensar. A tão debatida questão sobre se o treino cognitivo deve ser uma componente a adicionar ao currículo existente ou se deve ser "infundido" por meio de ajustamentos no currículo tradicional (McGuiness, 1993; McLure \& Davies, 1991) reflecte a existência dessas duas posturas distintas na concepção dos programas.

A presente proposta, embora tenha em conta os dois tipos de abordagem da intervenção cognitiva, situa, no entanto, a sua análise no âmbito da primeira, a qual se considera que oferece uma perspectiva mais abrangente dos programas e que permite ultrapassar a distinção entre programas "à parte" e de "infusão". Essa distinção, embora de certa forma correlativa à segunda, distingue-se dela por permitir alargar a análise a programas que podem ser ambíguos em relação a essa distinção, como o programa Filosofia para Crianças, que está na fronteira entre a "infusão" e o ensino "à parte", na medida em que procura promover as capacidades cognitivas através das humanidades, mais concretamente da filosofia, mas que se considera que treina capacidades gerais, como o pensamento crítico e o raciocínio dialógico, entre outros. A análise empreendida centrou-se nos programas cujo objecto de intervenção são capacidades gerais, uma vez que se considera que são aqueles que mais dúvidas têm levantado relativamente à sua eficácia (McLure \& Davies, 1991) e em relação aos quais a análise dos referenciais teóricos pode ser mais pertinente e eficaz. 


\section{O contributo das ciências cognitivas}

No âmbito das ciências cognitivas, constatase a existência de três grandes modelos cognitivos ou arquitecturas da mente baseados em outras três metáforas correspondentes: o modelo simbólico, que entende a mente como um processador em série e está relacionado com o modelo de processamento da informação que utiliza a imagem do computador como metáfora da mente humana; o conexionismo, baseado na metáfora do cérebro; e o modelo emergente das neurociências cognitivas, baseado na metáfora da plasticidade neuronal.

As ciências cognitivas integram actualmente um conjunto de abordagens distintas das questões relacionadas com a cognição que contrastam, em larga medida, com a perspectiva inicial do "cognitivismo clássico" e que se deve tanto à incorporação de novas disciplinas como à progressiva relevância assumida pelas neurociências cognitivas e os seus contributos para o conhecimento do cérebro, seu funcionamento, desenvolvimento e evolução. Como tal, oferecem novos dados e perspectivas sobre a cognição, os quais devem ser analisados e considerados em todas as suas dimensões e implicações. As questões do desenvolvimento podem e devem ser hoje enquadradas numa perspectiva mais vasta e mais complexa do desenvolvimento, que foi emergindo paralelamente ao avanço não só das investigações em neurociências cognitivas mas também ao contributo da biologia evolutiva e à teoria dos sistemas complexos. Considera-se que esses dois factores representam o surgimento de um novo paradigma que pode servir de instrumento à reflexão e análise crítica das teorias que subjazem aos PDC. Assumindo que as opções e os pontos de partida teóricos têm consequências sobre a organização dos programas e sobre os sujeitos e as capacidades que vão ser objecto de treino específico por parte desses programas, importa fazer uma análise do panorama das ciências cognitivas, na medida em que estas ocupam hoje um lugar chave no contexto do estudo da aprendizagem e da cognição.

A perspectiva adoptada na presente análise não é excludente dos modelos existentes; assenta antes na conviçção da incapacidade de esses modelos explicarem, cada um por si mesmo, isoladamente, a complexidade e multidimensionalidade da cognição e na consequente defesa de um modelo sistémico integrador que permita conjugar as diferentes aproximações ao problema da cognição e da intervenção cognitiva. $\mathrm{Na}$ base dessa postura está uma profunda convicção na sistematicidade da cognição, na medida em que se entende, com Gutiérrez Martínez (2005), que o funcionamento cognitivo é próprio de um sistema altamente organizado, embora não fechado, cujos componentes interactuam uns com os outros de forma complexa, afectando cada um a aplicação e o desenvolvimento dos outros, pelo que se torna impossível tratar qualquer um deles em profundidade sem fazer referência aos processos restantes. Entende-se ainda que esse sistema funciona em diferentes níveis interligados entre si: físico, cognitivo, emocional e social.

Parte-se da hipótese de que a abordagem sistémica da cognição permitirá conciliar as diferentes perspectivas existentes numa metateoria do desenvolvimento cognitivo, pelas razões que se adiantam a seguir:

- Representa uma teoria mais inclusiva e integradora do desenvolvimento cognitivo;

- Porque trabalha sobre sistemas complexos, abertos e não lineares;

- Explica a variação e a novidade (emergência) (Bunge, 2004; Gutiérez, 2005);

- Anula o carácter ou entendimento teleológico dos sistemas ao entendê-los como autoorganizativos;

- Torna patente e necessária a convergência (transdisciplinaridade) (Bunge, 2004).

Entende-se, ao mesmo tempo, que é consonante com essa metateoria - e, portanto, operativa e produtiva dentro de uma abordagem que se pretende sistémica - a teoria emergente no campo das neurociências cognitivas baseada na plasticidade neuronal, na medida em que acrescenta à perspectiva evolutiva e sistémica do desenvolvimento uma perspectiva sistémica do cérebro e seu funcionamento. Acrescenta às visões formalistas 
o nível físico de implementação, a matéria, e integra-a numa perspectiva biológica evolutiva de inter-relação com o meio que se considera transponível tanto para o campo comportamental como social, a qual, refutando o materialismo mas não renunciando à base física $\mathrm{e}$ fisiológica dos processos cognitivos, permite conservar "a hipótese de que os processos mentais possuem características peculiares que os distinguem de outras funções corporais" (Bunge, 2004, p. 73), evitando assim o reducionismo.

Nessa medida, entende-se ainda, em consonância com o pensamento de Morin (1992), que a perspectiva sistémica aplicada à cognição - não como uma teoria geral dos sistemas assente numa perspectiva holista, a qual se considera que seria redutora, mas uma teoria dos sistemas em termos "genéricos" e "generativos" que permita dar conta de toda a sua complexidade conceptual - impede, desta forma, a redução do que é complexo a um conceito ou teoria holista simplificadora. A teoria dos sistemas deve, desta forma, ser referida a um paradigma da complexidade que contemple incertezas e antagonismos ao juntar termos mutuamente interconectados mas simultaneamente antagónicos, abrindo-se, assim, à incerteza e à imprevisibilidade. Tal como para Bunge (2004), também Morin (1992, p. 373) considera que o sistema não deve ser concebido apenas como uma unidade global, mas sim em termos de uma unitas multiplex: "os exemplos dos sistemas atómicos, biológicos e sociais mostram-nos que um sistema não é apenas uma composição da unidade a partir da diversidade, mas também uma composição de diversidade interna a partir da unidade".

Assim, temos, por um lado, uma metateoria representada pela perspectiva sistémica e, por outro, uma teoria - da plasticidade neuronal - que, integrando-se numa abordagem e num entendimento sistémicos, permite analisar a cognição e os fenómenos mentais a partir de uma perspectiva distinta das existentes até o momento. Considera-se a teoria dos sistemas dinâmicos como uma metateoria, na medida em que especifica regras gerais metodológicas de abordagem dos fenómenos em geral e, como tal, é aplicável a diversos fenómenos em diversos campos do saber e representa um marco teórico-metodológico de carácter geral e flexível susceptível de ser aplicado em distintos campos de investigação (Gutiérrez Martínez, 2005). Nesse sentido, é susceptível de incluir ou ser compatível com teorias que, embora se apliquem a âmbitos específicos da realidade - no caso das neurociências cognitivas ao cérebro e seu funcionamento -, o fazem desde uma abordagem sistémica. A máxima da perspectiva sistémica é que a complexidade não pode ser simplificada (Morin, 1992), na medida em que estabelece implicação mútua e introduz um conceito complexo de causalidade que implica três conceitos indissociáveis: sistema, interacção e organização. Nessa medida, representa uma nova forma de pensar que estimula uma praxis complexa.

Assim, entende-se que, apesar de que na linguagem da ciência as metáforas são inevitáveis (Lewotin, 1998), existem metáforas mais apropriadas do que outras no que diz respeito ao estudo da cognição. Do ponto de vista do paradigma da complexidade, o desenvolvimento emergiu como um processo complexo, dinâmico, que contempla variáveis com múltiplos níveis de análise. Deve explorar influências recíprocas entre processos biológicos e psicológicos e as condições ambientais e contextuais. A interacção dinâmica existente entre indivíduo e contexto no desenvolvimento supõe que cada parte seja transformada e influenciada pela outra. Por isso, as metáforas usadas para explicar o desenvolvimento, sejam mecanicistas, organicistas ou contextualistas, baseadas na ideia de um tempo contínuo e mutuamente excludentes, não são adequadas para explicar o desenvolvimento humano.

Entende-se que a teoria da complexidade oferece ao estudo da cognição: a) uma abordagem sistémica/ complexa do desenvolvimento; b) Uma perspectiva sistémica do cérebro como sede da cognição fundada no modelo da plasticidade neuronal; c) a necessidade de um enfoque transdisciplinar que permita explicar a complexidade e multidimensionalidade do sujeito e seu desenvolvimento.

Considera-se ainda que os sistemas auto-organizativos são plásticos, uma vez que são mutáveis, 
estão em constante inter-relação com o meio, têm uma história que não deve ser descurada e um grau de complexidade que não se compadece com metáforas reducionistas. Tanto os organismos vivos como o cérebro são exemplos de sistemas auto-organizativos, plásticos e complexos que devem ser entendidos como tal. Nos organismos vivos, a plasticidade manifesta-se como plasticidade fenotípica, entendendo por fenótipo a expressão do genótipo (informação genética) num determinado ambiente (fenótipo = genótipo + ambiente). No cérebro, a plasticidade manifesta-se como neuroplasticidade, a qual é um caso da plasticidade fenotípica e uma das características centrais do cérebro como sede da cognição.

\section{O modelo de análise}

\section{Constructos fundamentais}

No contexto teórico-conceptual em que se situa a investigação e tendo em conta hipótese, princípios, referências e orientações seguidas, definiu-se a teoria da complexidade como paradigma de referência para a análise dos PDC seleccionados. Nessa medida, ela enquadra a construção do modelo de análise. Por sua vez, a perspectiva sobre o sujeito emergente das ciências cognitivas é um dos eixos ou constructos fundamentais do modelo aqui proposto: entendido como plástico, multidimensional e narrativo em relação ao processo de construção e reconstrução da sua identidade. A ideia de multidimensionalidade surge aqui ligada à ideia de complexidade; nesse sentido, entende-se por sujeito multidimensional um sujeito bio-psico-social, que é uma construção bioantropológica cuja identidade não é monolítica, uma vez que se constrói entre distintas e diferentes dimensões interligadas entre si e à qual subjaz a unidade de uma consciência. Como afirma Edgar Morin (1999, p. 13), "as unidades complexas, como o ser humano ou a sociedade, são multidimensionais; o ser humano é simultaneamente biológico, psíquico, social, afectivo, racional", e ser complexo implica precisamente a unidade dessas várias dimensões.
O outro eixo ou constructo fundamental é o de plasticidade neuronal: entendida como a capacidade do cérebro para configurar-se e reconfigurar-se ao longo de toda a vida (as redes neuronais organizamse e reorganizam-se de acordo com a experiência dos indivíduos e podem ser modificadas ao longo de toda a vida), introduz a dimensão da autonomia e uma possibilidade criadora que instaura o sujeito como escultor do seu próprio cérebro e abre a educação à dimensão da possibilidade. O sujeito da plasticidade, não sendo uma essência nem uma substância, também não é uma ilusão: é um sujeito multidimensional, é o resultado da resiliência, é uma realidade complexa que inclui um sujeito natural, um sujeito de representação e um sujeito corporizado. Inclui processos mentais (sensações, percepções, recordações, crenças, inferências, volições e sentimentos), os seus e os dos demais com que se relaciona; é, enfim, um sujeito comunicacional.

\section{Construção e aplicação}

A construção e a aplicação do modelo de análise tomaram em consideração: os modelos e teorias de referência dos programas analisados, as perspectivas sobre o sujeito da educação e seu desenvolvimento, a origem dos programas e os contextos em que se propõem intervir. O modelo proposto foi aplicado a um conjunto de quatro programas gerais de habilidade seleccionados de acordo com a sua representatividade relativamente à diversidade de programas existentes o programa de Filosofia para Crianças (FC), de Lipman (1988a, 1988b, 1989, 1990, 1996, 1997, 2000, 2004); o programa Comprender e Transformar (C\&T), de Joaquín Mora (1998a, 1998b); o Programa de Promoção Cognitiva (PPC), de Almeida e Morais (1994, 2002); e o programa Aprender com todo o Cérebro (ATC), de Williams (1986). Foi definido um conjunto de variáveis, divididas em categorias, no intuito de criar um instrumento de análise que foi posteriormente aplicado aos programas seleccionados. As categorias definidas abarcam os distintos aspectos e dimensões que constituem os programas analisados (teorias, objectivos, estrutura, métodos, actores 
envolvidos e contextos), o que permitiu comparar programas e cruzar diferentes variáveis.

\section{Variáveis e categorias}

\section{Origem}

Relativamente a esta variável consideram-se duas categorias: as condições de emergência do programa, as quais incluem a data de surgimento, a proveniência académica dos autores e a origem da iniciativa de construir o programa em causa; e o diagnóstico da situação ou problema que está na origem e determina a legitimidade ou necessidade da intervenção, e relaciona-se com o contexto institucional ou educativo onde surgiu, assim como os referentes e argumentos teóricos e práticos utilizados para justificar a necessidade da intervenção e os problemas ou questões que procura resolver no quadro desse contexto. Trata-se de aceder ao nível do questionamento inicial dos autores, no intuito de definir os problemas a que o programa procura dar resposta, a que nível emergem esses problemas e em que contextos. Tem uma dimensão histórica relativa às condições e factores que estão na origem de um determinado programa e que influenciam o tipo de intervenção proposta.

\section{Orientação}

Consideram-se, no que diz respeito a esta variável, duas categorias: problemática interna do programa, relacionada com a perspectiva em que se situa relativamente à intervenção cognitiva, ao seu papel e necessidade, e que permite determinar os significados atribuídos pelos autores às dificuldades observadas, aos elementos utilizados para interpretar essas dificuldades e delimitar a intervenção, assim como a forma como é conceptualizada a natureza das mudanças ou efeitos a produzir. Essa categoria permite ainda esclarecer a forma como são pensados aspectos que transcendem os factores individuais de desenvolvimento, como problemas sociais, culturais, económicos e epistemológicos (Sorel, 1994). Uma segunda categoria incide sobre as intenções ou objectivos gerais dos programas que se considera que delimitam o campo e os domínios de intervenção de cada PDC e determinam o tipo de proposta apresentada, definindo estas duas categorias a sua orientação geral.

\section{Fundamentação teórica}

A variável fundamentação teórica incide sobre os referenciais teóricos de cada programa, partindo da perspectiva de que esses referenciais determinam o tipo de intervenção proposta, na medida em que estão relacionados com a perspectiva sobre o sujeito, o seu funcionamento e desenvolvimento cognitivo e a melhor forma de fomentar o treino das habilidades cognitivas. Essa é uma das assumpções principais da presente proposta, daí a relevância desta variável.

O campo dos fundamentos, referências e princípios teóricos é determinante e central em relação às orientações gerais do programa e à sua implementação. Representa o conjunto de conhecimentos e o quadro teórico e conceptual que serve de referência e em que se fundamenta a proposta de intervenção contida em cada um dos programas. Está relacionado com a definição de conceitos e com as suas finalidades em termos de valores, ideologias e concepções. Está relacionado tanto com a necessidade de conceptualizar a natureza da mudança/transformação a produzir pela intervenção como com os processos implicados nessa mudança e nessa intervenção. Está subjacente à própria descrição e à argumentação dos efeitos a produzir, bem como à própria possibilidade da sua produção. Essa dimensão teórica é, então, aquilo que suporta e determina a prática, a intervenção. Assim, esse critério responde à necessidade de formalizar o enquadramento teórico das diferentes práticas.

Dependendo das referências teóricas explícitas ou dos modelos implícitos dos autores dos programas, o sentido que se dá à noção de desenvolvimento cognitivo, de potencial do sujeito e das suas dificuldades pode ser distinto em cada um deles. Essas delimitações conceptuais e teóricas servem ainda para identificar o objecto da intervenção e para compreender os procedimentos e as escolhas pedagógicas propostas. Dão, 
em suma, coerência - quer teórica, quer prática - aos programas. Por isso, a questão inicial será saber que opções teóricas, explícitas ou implícitas, foram feitas pelo autor ou autores de cada um dos programas. Trata-se de determinar como ele se terá posicionado em relação aos diferentes modelos teóricos e, mais concretamente, àquele que adoptou para elaborar a sua proposta, ao mesmo tempo tentando perceber em que medida é que essas opções orientaram o seu trabalho.

A análise dos elementos teóricos de cada programa poderá possibilitar comparações e distinções.

A primeira categoria correspondente a esta variável refere-se aos modelos teóricos de referência do programa, principalmente os modelos cognitivos. Quanto a estes últimos, embora relacionados com as influências teóricas, situam-se num âmbito mais restrito da adesão a um determinado modelo da cognição, que serve de base ao programa e que delimita as dimensões cognitivas que visam estimular e as ferramentas valorizadas e/ou utilizadas.

O objectivo desta variável de análise é também identificar tendências dominantes e emergentes nos programas a analisar, tentando simultaneamente compreender se o paradigma da complexidade está a emergir como modelo em alguns PDC e, se tal se verifica, enquadrado em que pressupostos e referências teóricas e em que perspectiva sobre o sujeito.

A segunda categoria decorre da primeira e complementa-a: refere-se aos conceitos- chave utilizados no discurso sobre a intervenção e sobre as capacidades, ilustra os modelos de referência de cada programa ao realçar os conceitos que sustentam os discursos dos seus autores.

A terceira categoria refere-se à interdiscursividade entendida segundo a perspectiva de Jörg, Davis e Nickmans (2007), relativamente à necessidade de praticar a interdiscursividade ao nível das ciências da educação, utilizando discursos distintos e provenientes de diversos campos do saber, dialogar com outras disciplinas e ligada à prática da transdisciplinaridade relacionada com a utilização desses saberes, discursos e metodologias na compreensão e intervenção sobre a realidade.
Uma quarta categoria faz referência à perspectiva sobre as capacidades presente no programa, que inclui as capacidades trabalhadas e valorizadas pelo programa e que contempla a forma como é definido o funcionamento cognitivo dos sujeitos e as referências às distintas capacidades ou dimensões do funcionamento cognitivo deles (as emoções, a corporeidade, a comunicação, a expressividade e a intencionalidade), mais directamente relacionado com a multidimensionalidade. Por dimensões cognitivas entendem-se as componentes da cognição que são contempladas pelo programa, aquelas cuja implementação visa estimular e que podem estar relacionadas com a experiência sensível, com os factores emocionais, com a promoção de uma inteligência reflexiva e autorreflexiva (metacognitiva), com os factores sociais da cognição ou com os factores neuronais. Com esse critério pretende-se também perceber como se reconhecem e estabelecem as interacções entre as diferentes componentes do funcionamento cognitivo.

Por último, a categoria sobre o desenvolvimento e funcionamento mental do sujeito inclui as perspectivas sobre o desenvolvimento e funcionamento cognitivo do sujeito e os factores que o influenciam, e pretende determinar a forma como cada programa se situa em relação às distintas perspectivas científicas existentes sobre eles e em que medida elas influenciam a forma como é entendida e estruturada a intervenção.

\section{Sujeito da Intervenção}

Cada programa, tanto pelas opções teóricas que contém, como pelas práticas que propõe, representa, implícita ou explicitamente, uma perspectiva sobre o sujeito, suas características, seu desenvolvimento e faculdades. Daí a necessidade de integrar os PDC a analisar no campo mais vasto de uma teoria global do sujeito, na problemática geral da intervenção educativa, da compreensão global do funcionamento do sujeito e na necessidade de integração dos fenómenos psicológicos e cognitivos nessa teoria ou teorias.

O objectivo desta variável é identificar, em linhas gerais, qual é o perfil do sujeito que está por detrás de 
cada proposta, como define cada programa, de forma explícita ou implícita, o pensador eficaz, competente, rigoroso, especialista ou autónomo que pretende formar. Está centrado no sujeito no seu todo ou aponta apenas para algumas características ou dimensões específicas? Que características deve esse sujeito reunir para que o método atinja os seus objectivos? Ao mesmo tempo, esse critério permite relacionar cada perfil de sujeito com o sujeito multidimensional da plasticidade neuronal.

Incluem-se na dimensão do sujeito as categorias relativas ao público-alvo, relativamente à faixa etária, ao nível de ensino e tipo de características cognitivas e de aprendizagem que lhe são atribuídas e aquelas que são consideradas relevantes relativamente à intervenção proposta; o papel atribuído ao aluno, na medida em que a análise desse papel permite estabelecer como é entendida a sua actuação e a margem de manobra que lhe é permitida, no âmbito de cada proposta metodológica e dos modelos de desenvolvimento presentes em cada programa. A questão é: que espaços de possibilidade abrem os diferentes programas à construção do sujeito? Partindo da hipótese de que esse espaço de possibilidade será distinto nos diversos programas a analisar, como é entendida e orientada a sua acção? Que ruptura pretende provocar relativamente ao que lhe é familiar e que relação com o já sabido e já adquirido? Que continuidade e que ruptura com a sua experiência anterior? Que preocupação com as especificidades de cada aluno? Que grau de personalização presente nos diversos programas? Que preocupação com os processos de subjectivação, com a imagem de si do sujeito e com as suas expectativas? Que tipos de interacções são promovidas? Que tipo de consciência ou autoconsciência é fomentada?

\section{Formador/Aplicador}

O papel do formador/aplicador é relevante na medida em que cada programa impõe ao formador tomadas de posição relativamente ao desenvolvimento, à inteligência, à aprendizagem, ao mesmo tempo que lhe abre um espaço de intervenção pessoal que pode ser mais flexível ou mais rígido, mais vasto ou mais restrito.

Aplicar um programa exige do formador adesão aos princípios e ao tipo de intervenção por ele proposta, implicação pessoal que o torna também sujeito, que apela ao seu projecto educativo particular e à mobilização dos seus conhecimentos e saberes. Cada programa pode ser, também neste domínio, mais flexível ou mais rígido, dar mais espaço a uma apropriação pessoal pelo aplicador e a uma adaptação ao contexto particular em que se situa a sua acção ou ser mais fechado a essa apropriação e aos contributos que possa trazer cada aplicador em cada contexto particular.

Consideram-se relativamente a esta variável as seguintes categorias: papel atribuído ao formador, no que diz respeito à forma como é entendida a sua actuação relativamente à aplicação do programa e quais são as competências que deve assumir no quadro da implementação e aplicação ao contexto no sentido de perceber se é visto como um executor das tarefas indicadas no programa, se é um intérprete e tradutor das ideias aí expressas ou se é ele próprio criador de estratégias de aplicação a partir dos materiais e abordagens sugeridos; as condições de acesso referem-se aos requisitos profissionais e académicos como à própria formação específica no programa, considerada necessária para a sua aplicação; e o tipo de formação específica oferecida no âmbito do programa a aplicar.

\section{Objecto da intervenção}

Esta variável refere-se à proposta de intervenção propriamente dita e às suas características intrínsecas, no intuito de pensar os domínios de aplicação do programa e a sua operacionalização. Contempla as categorias: operacionalização, relacionada com a metodologia utilizada e a estrutura do programa; os efeitos pretendidos com a sua aplicação de uma forma geral; os objectivos especificos das sessões; as modalidades da intervenção ou actividades propostas, relacionados com os conteúdos, as situações de aprendizagem que proporciona, o tipo de actividade 
que propõe. Os suportes materiais referem-se ao tipo de materiais que proporciona, os recursos que exige e a forma como estão organizados e relacionados com as actividades (livros de texto, fichas e imagens, entre outros). A sequência ou estrutura do programa está relacionada tanto com a sequência de actividades como com a sequência dos processos ou técnicas treinados e a forma como se estruturam as sessões. Finalmente, os resultados ou avaliações que, no caso da presente análise, se referem aos instrumentos de avaliação propostos pelos autores dos programas e aos resultados referidos também pelos próprios autores relativamente às experiências anteriores de aplicação.

No campo dos objectivos, seguindo a proposta de Maryvonne Sorel (1992), pretende-se analisar tanto os perseguidos por cada programa, isto é, os objectivos operacionais, como o tipo de efeitos pretendidos. No que diz respeito aos primeiros, ter-se-á em conta, simultaneamente, a descrição do conteúdo da intervenção pedagógica e as performances observáveis no fim da intervenção, correspondendo a competências e capacidades cognitivas desenvolvidas pela intervenção. Será a partir da análise dos objectivos que se poderá posteriormente avaliar os resultados obtidos. No que concerne aos efeitos pretendidos, trata-se de efeitos observáveis para além da intervenção e do material previsto por cada programa: os efeitos a longo prazo, em situações sociais e profissionais; os efeitos que correspondem às transferências, à extensão dos campos operatórios e à generalização das atitudes e dos procedimentos considerados eficientes. Mais uma vez, no intuito de acentuar a importância das transferências e transposições para situações sociais. De notar ainda que estas são potenciadas por factores contextuais e de índole pessoal, social e afectiva.

Os efeitos pretendidos são entendidos no sentido mais genérico das transformações cognitivas e comportamentais que se espera que o programa opere nos sujeitos e que devem ser verificáveis no fim da intervenção. Também contemplam os objectivos específicos de cada uma das sessões, na medida em que estes permitem especificar os processos cognitivos trabalhados com os programas e perceber a forma como são sequenciados e estruturados. Também o tipo de actividades propostas é objecto de análise no sentido de esclarecer a natureza dessas actividades e de entender a forma como se concretiza a proposta de intervenção em análise. Da mesma forma, tomam-se em consideração os suportes materiais oferecidos pelos programas e necessários à realização das actividades propostas e sua natureza. Para finalizar, inclui-se uma categoria relacionada com os resultados ou avaliação que não se centra, como tem vindo a ser referido, nos resultados obtidos por meio de alguma intervenção específica, mas nos instrumentos e critérios de avaliação dos resultados propostos por cada programa e e na referência feita pelos autores aos resultados obtidos até o momento.

O que se pretende com uma análise da estruturação dos programas é definir se existe uma sequência, uma organização interna na qual os exercícios propostos apresentem progressão, e de que tipo é a progressão proposta por cada um; se o programa está dividido por níveis ou fases, como se relacionam as diferentes fases entre si e com os objectivos gerais do programa; e como é que os modelos teóricos, de forma explícita ou implícita, determinam essa estrutura; se explicitam de forma rigorosa as relações previstas entre as opções feitas e as modelizações realizadas, os objectos a transformar e a desenvolver e o modo de trabalho pedagógico previsto para os formadores/ aplicadores.

\section{Ambientes/contextos de intervenção}

Através desta categoria pretende-se determinar as preocupações que existem em cada programa com o contexto social em que são aplicados, os problemas que procuram resolver com os factores culturais e históricos, enquadrados naquilo que De Corte (1990) designa como powerful learning environments. Tratase de analisar o ambiente da formação e os campos sociais referentes, relacionando-os com a ideia de inteligência social.

Ainda neste campo pretende-se determinar a importância atribuída às transferências e transposições 
entre as situações de formação e as situações sociais, tentando ainda perceber que tipos de transferências são valorizadas e promovidas tomando como referência a distinção entre transferência de "alta densidade" e de "baixa densidade", ou transferência "próxima" e "distante".

Também se analisa a relevância atribuída ao contexto de aplicação do programa e a forma como se entende que pode influenciar o sucesso ou insucesso da intervenção, assim como a possibilidade de adaptação do programa a distintos contextos.

Nesta variável incluem-se as seguintes categorias: características do contexto de implementação, tal como é referido e definido pelo autor (ou autores) do programa, e contempla o nível de ensino em que vai ser aplicado, a forma como é organizado o trabalho nas diferentes sessões e de acordo com as diferentes actividades; a relevância desse contexto, relativamente à forma como está organizada a proposta de intervenção, o tipo de actividades e mesmo as capacidades treinadas, no intuito de perceber se são tidas em conta as variáveis relacionadas com o contexto; e a possibilidade de adaptação do programa a diferentes contextos, tanto no que diz respeito à flexibilidade da sua estrutura e à sua abertura à adaptação e às mudanças necessárias para fazê-la, a forma como se relaciona e integra no contexto institucional e organizacional da escola ou outras instituições de formação, a relação que estabelece com as aprendizagens e os currículos escolares, a forma como se pode adaptar às diferentes características dos alunos, a forma como se relaciona com os diferentes agentes significativos professores, pais e pares.

\section{Resultados obtidos}

\begin{tabular}{|c|c|c|c|c|}
\hline & $\begin{array}{c}\text { Programa de } \\
\text { promoção cognitiva }\end{array}$ & $\begin{array}{c}\text { Programa Compreender } \\
\text { e transformar }\end{array}$ & $\begin{array}{l}\text { Programa Aprender } \\
\text { com todo o cérebro }\end{array}$ & $\begin{array}{c}\text { Programa Filosofia } \\
\text { para crianças }\end{array}$ \\
\hline Fundamentos teóricos & Modelo Cognitivista & Modelo Cognitivista & $\begin{array}{c}\text { Funcionamento } \\
\text { Bilateral dos } \\
\text { Hemisférios Cerebrais }\end{array}$ & $\begin{array}{c}\text { Filosofia e Pensamento } \\
\text { Complexo }\end{array}$ \\
\hline Sujeito & $\begin{array}{c}\text { Receptor/Executor do } \\
\text { Programa }\end{array}$ & $\begin{array}{l}\text { Receptor/Executor do } \\
\text { Programa }\end{array}$ & Multidimensional & $\begin{array}{l}\text { Multidimensional e } \\
\text { Integrado }\end{array}$ \\
\hline Intervenção proposta & $\begin{array}{c}\text { Rígida e Fechada } \\
\text { "Orientada para os } \\
\text { fins" }\end{array}$ & $\begin{array}{c}\text { Rígida e Fachada } \\
\text { "Orientada para os } \\
\text { fins" }\end{array}$ & $\begin{array}{c}\text { Flexível e Aberta } \\
\text { "Orientada para a } \\
\text { possibilidade" }\end{array}$ & $\begin{array}{c}\text { Flexível e Aberta } \\
\text { "Orientada para a } \\
\text { possibilidade" }\end{array}$ \\
\hline $\begin{array}{c}\text { Integração em } \\
\text { diferentes contextos } \\
\text { escolares }\end{array}$ & Difícil Integração & Difícil Integração & $\begin{array}{l}\text { Possibilidades de } \\
\text { Integração }\end{array}$ & $\begin{array}{l}\text { Possibilidades de } \\
\text { Integração }\end{array}$ \\
\hline
\end{tabular}

A aplicação do modelo aos programas seleccionados demonstrou que alguns dos programas analisados entendem o sujeito como receptor/executor da intervenção proposta (PPC; C\&T), enquanto outros o entendem como multidimensional e autónomo (ATC; FC).

A intervenção proposta por alguns dos programas é rígida e fechada (PPC; C\&T) e pode ser entendida como uma espécie de "programação cognitiva" (Matos \& Caramelo, 2004), apoiada numa intervenção orientada para os fins, enquanto outros propõem uma intervenção flexível e aberta, orientada para a possibilidade (ATC; FC).

Alguns programas apresentam mais possibilidades para serem aplicados em diferentes contextos escolares e educativos (ATC; FC), enquanto para outros essa possibilidade não é tão evidente e pode ser confrontada com alguns problemas relacionados com a sua estrutura, objectivos e metodologia (PPC, C\&T).

A análise empreendida tornou ainda evidente que, contrariamente àquilo que afirmam alguns autores 
(Nickerson, Perkins \& Smith, 1985), existe estreita relação entre os referenciais teóricos de que parte cada programa e o tipo de intervenção que propõem, por isso, as teorias do desenvolvimento e do funcionamento cognitivo, às quais, por sua vez, subjazem determinadas perspectivas sobre o sujeito a educar; o papel do professor e das aprendizagens escolares são determinantes relativamente à elaboração e estruturação das propostas e estão patentes na forma como estão concebidas e organizadas. O modelo proposto pode contribuir para repensar os programas existentes e propor novas formas de intervir nesse campo em particular.

\section{Conclusões}

A investigação organizou-se em torno a três eixos que estruturam a análise: a) a realidade dos programas; b) os modelos disponíveis; e c) a análise das implicações pedagógicas da sua implementação na realidade educativa em que pretendem intervir. Esses eixos foram considerados no horizonte da emergência de um novo entendimento do sujeito como complexo e multidimensional e no âmbito de uma pedagogia da possibilidade, que pretende abrir novos espaços de reflexão sobre esse mesmo sujeito, abertos à construção da sua autonomia e liberdade e centrados no ideal antropológico de realização plena da sua humanidade. Entende-se que os PDC, enquanto instrumento ou aparato pedagógico de formação dos sujeitos, podem e devem ser questionados e analisados no âmbito dessa perspectiva, sob pena de não passarem de meras propostas de "programação cognitiva" cujo objectivo não seria mais do que a reprodução de uma determinada perspectiva sobre a cognição e o funcionamento e desenvolvimento cognitivo dos sujeitos, situada apenas num nível formal e ignorando dimensões importantes dos seus modos de ser e pensar, como o nível físico de implementação, o nível emocional de implicação, reflexão e acção e o nível social de construção intersubjectiva de tramas vitais e de significados. Consequentemente, encerra o risco de que as propostas de formação sejam entendidas como uma oferta já feita e acabada, isolada de outras dimensões do currículo, fechada à complexidade e à plasticidade dos sujeitos e das suas formas de acção e pensamento, em que este é considerado objecto da intervenção, em vez de autor da formação (Matos \& Caramelo, 2004).

O desenvolvimento da investigação e a construção do modelo de análise permitiu avaliar algumas dúvidas e suspeitas iniciais:

- Confirmar que o debate existente entre os autores dos programas sobre a melhor forma de intervenção continua em aberto, assim como a existência de algumas indefinições e alguns problemas não resolvidos ao nível da implementação e avaliação;

- Isolar os referenciais e modelos teóricos da cognição mais relevantes em termos da intervenção, o que confirmou a percepção inicial de que, apesar da diversidade de propostas existentes e a tendência crescente para uma maior heterogeneidade de influências, os modelos dominantes continuam a ser o de processamento da informação, o de desenvolvimentalista de Piaget e o sócio-histórico de Vygotsky, com um claro predomínio do primeiro;

- Confirmar também a escassa influência ou relevância de modelos emergentes de campos alheios à psicologia cognitiva ou do desenvolvimento como o modelo neurocientífico do funcionamento cerebral.

O modelo de análise proposto é um modelo interpretativo, e não meramente descritivo; é reflexivo na medida em que questiona e problematiza as propostas de intervenção. Nesse sentido, apela às capacidades críticas do investigador/aplicador e está aberto ao aperfeiçoamento. O seu carácter inovador reside tanto no facto de partir de um modelo explícito de análise, como na natureza e origem desse modelo, nos constructos e nas variáveis propostos, ou ainda no facto de ser um modelo compreensivo 
e aberto a adaptações futuras e a outros programas ou realidades. Nesse sentido, a proposta de modelo de análise não é uma proposta acabada ou um ponto de chegada, mas um ponto de partida para futuras investigações.

Considera-se, no entanto, que ele abre a possibilidade à aplicação e à utilização de modelos da cognição e de conhecimentos vindos de âmbitos exteriores ao campo tradicional, quer da psicologia, quer da educação. Permite também lançar um novo olhar sobre a intervenção cognitiva, um olhar mais problematizador e questionador que pode permitir pensar as intervenções existentes noutros termos, adaptar os programas existentes ou criar novos. Pode ainda ser útil tanto no que se refere às escolhas de programas pelas escolas, quer à investigação sobre o desenvolvimento e a intervenção cognitiva, e pode servir de base para relançar o debate em torno da educabilidade cognitiva e do currículo para o pensar.

A aplicação do modelo e a conceptualização na qual se baseia deixam também algumas questões em aberto: o que será um tipo de intervenção consonante com o paradigma proposto e com os conceitos de referência da análise? Faz sentido continuar a aplicar e a investir em programas que se entende que derivam e promovem perspectivas redutoras do desenvolvimento e do funcionamento mental dos sujeitos? Que critérios devem prevalecer na selecção de programas a aplicar em cada contexto?

Os instrumentos conceptuais da investigação permitiram interrogar os PDC como aparatos pedagógicos relativos às possibilidades que abrem e promovem: a perspectiva de Larrosa (1999) relativa à relação entre literatura e filosofia no campo da educação pode aqui ser aplicada, uma vez que os conceitos definidos foram utilizados no intuito de questionar o óbvio e ampliar o possível. Questionouse em que medida os programas ampliam as possibilidades narrativas dos sujeitos e as capacidades plásticas dos cérebros. De que forma os programas, como recursos pedagógicos, abrem possibilidades ou apenas permitem o já previsto, já pensado, já lido e já dito, para além da ortodoxia das ideias estabelecidas? Nesse sentido, o mesmo aparato conceptual permitiu pensar a intervenção para além da mera "programação cognitiva" em que alguns programas podem converter-se. Os conceitos de complexidade, sistema, plasticidade, transdisciplinaridade e interdiscursividade podem constituir novos conceitos-chave para o entendimento da cognição e podem funcionar como ideias-ponte (Bunge, 2004) para a necessária convergência entre disciplinas. A perspectiva defendida abre a possibilidade de novas formas de investigação e apela a ultrapassar as fronteiras entre as disciplinas - implica, nesse sentido, a transgressão de algumas ideias estabelecidas e o surgimento de novas formas de investigação e cooperação entre domínios do saber humano -; foi nesse sentido que se defendeu o exercício da transdisciplinaridade e a prática da interdiscursividade. Considera-se que a teoria da educação pode ser, neste âmbito, o campo principal de reflexão e debate sobre as questões e realidades emergentes que permita articular as preocupações pedagógicas ou psicológicas com questões culturais, sociais e políticas, definindo prioridades, objectivos e possibilidades.

\section{Referências bibliográficas}

ALMEIDA, Leandro; MORAIS, Maria F. Programa de Promoção Cognitiva. 4. ed. Braga: Psiquilibrios, 2002. Programa Promoção Cognitiva. Braga: Didálvi, 1994. BERNAL, Antonio; GONÇALVES, Teresa. Identidade narrativa e plasticidade cerebral: algumas propostas pedagógicas. Revista Portuguesa de Pedagogia, v. 42 (1), p. 27-43, 2008.

BUNGE, Mario. Emergencia y convergencia: novedad cualitativa y unidad del conocimiento. Barcelona: Gedisa, 2004.

CAPRA, Fritjof. La trama de la vida. Barcelona: Anagrama, 1998.

DE CORTE. Erik. Towards powerful learning environments for the acquisition of problem solving skills. European Journal of Psychology of Education, v. 5, p. 5-19, 1990.

FERNÁNDES BALlESTEROS, Rocío; GENOVESE, Santiago; MIALARET, Gaston; OSORIO MELÉNDEZ, Hugo. Evaluación de los programas de desarrollo de la inteligencia. 
Paris: UNESCO, 1984. Disponível em: <http://unesdoc.unesco. org/images/0006/000621/062176so.pdf>. Acesso em: jul. 2006. GUTIÉRREZ MARTÍNEZ, Francisco Teorías del Desarrollo Cognitivo. Madrid: McGraw-Hill, 2005.

HAMERS, Johan H. M.; OVERTOOM, Mitrees TH. Programas europeus de ensinar a pensar: tendências e avaliação. Inovação, v. 11, p. 37-46, 1998.

HUTEAU, Michel; LOARER, Even. Comment évaluer les méthodes d'éducabilité cognitive? L'Orientation Scolaire et Professionnelle, v. 21(1), p. 47-74, 1992.

JÖRG, Ton; DAVIS, Brent; NICKMANS, Goele. Towards a new, complexity science of learning and education. Educational Research Review, v. 2, p. 145-156, 2007.

LARROSA, Jorge. Dar a ler, dar a pensar... quem sabe. Entre literatura e filosofia. In: Walter KOHEN; LEAL, Bernardina. Filosofia para crianças em debate. Petrópolis: Vozes, 1999. LEWONTIN, Richard. A tripla hélice. Gene, organismo e ambiente. Lisboa: Edições 70, 1998.

LIPMAN, Matthew. El Descubrimiento de Harry. Madrid: Ediciones de la Torre, 1988a.

Elfie. Madrid: Ediciones de la Torre, 2000.

A filosofia vai à escola. Sao Paulo: Summus Editorial, 1990.

Kyo y Gus. Madrid: Ediciones de la Torre, 1997.

Lisa. Madrid: Ediciones de la Torre, 1988b.

Natasha: aprender a pensar con Vygotsky: una teoría narrada en clave de ciencia ficción. Barcelona: Gedisa, 2004.

Pensamiento complejo y educación. Madrid: Ediciones de la Torre, 1996.

Pixie. Madrid : Ediciones de la Torre, 1989.

MATOS, Manuel; CARAMELO, João. A racionalidade compósita como modelo de análise das práticas de formação contínua. Educação, Sociedade e Culturas, v. 22, p. 27-40, 2004.

McGUINESS, Carol. Teaching thinking: new signs for theories of cognition. Educational Psychology, v. 13 (3-4), p. 305-316, 1993.

McLURE, Stuart.; DAVIES, Peter. Learning to think, thinking to learn: the proceedings of the 1989 OECD conference. Oxford: Pergamon Press, 1991.

MORA, Joaquín. El programa comprender y transformar: bases, metodología y evaluación. Sevilla: Repiso Libros, 1998a.
. El programa comprender y transformar: materiales para la educación primaria. Sevilla: Repiso Libros, 1998b.

MORIN, Edgar. From the concept of system to the paradigm of complexity. Journal of Social and Evolutionary Systems, v. 15 (4), p. 371-385, 1992.

. Los siete saberes necesarios a la educación del futuro. Paris: UNESCO, 1999.

NICKERSON, Raymond; PERKINS, David; SMITH, Edward. Enseñar a pensar. Barcelona: Paidós, 1985.

PERRAUDEAU, Michel. Métodos cognitivos em educação: aprender de outra forma na escola. Lisboa: Instituto Piaget, 1996.

SOREL, Maryvonne. Peut-on classer les méthodes d'éducabilité cognitive? L'Orientation Scolaire et Professionnelle, v. 21 (1), p. $75-105,1992$.

. Pratiques nouvelles en éducation et en formation.

L'éducabilité cognitive. Paris: L'Harmattan, 1994.

YUSTE HERNANZ, Carlos. Los programas de mejora de la inteligencia. Madrid: Ciencias de la Educación Preescolar y Especial, 1997.

WILLIAMS, Linda. Aprender con todo el cerebro. Estrategias y modos de pensamiento: visual, metafórico y multisensorial. Barcelona: Martínez Roca, 1986.

TERESA GONÇALVES, doutora em ciências da educação (teoria da educação) pela Universidade de Sevilha, é investigadora-auxiliar da Unidade de Investigação Educação e Desenvolvimento da Faculdade de Ciências e Tecnologia da Universidade Nova de Lisboa. Publicações recentes: Plastic Brains and Complex Systems: a transdiciplinary approach to education and the cognitive sciences (In: Karanika-Murray; Wiesemes (Ed.). Exploring avenues to interdisciplinary research: from cross - to multi - to interdisciplinarity, Nottingham University Press, 2009); em coautoria com Bernal, A. Identidade narrativa e plasticidade cerebral: algumas propostas pedagógicas [Revista Portuguesa de Pedagogia, v. 42 (1), p. 27-43, 2008]. E-mail: $\operatorname{tprg} @$ fct.unl.pt.

Recebido em maio de 2010

Aprovado em julho de 2010 
Esquema 1 - Modelo de Análise: Paradigma da complexidade

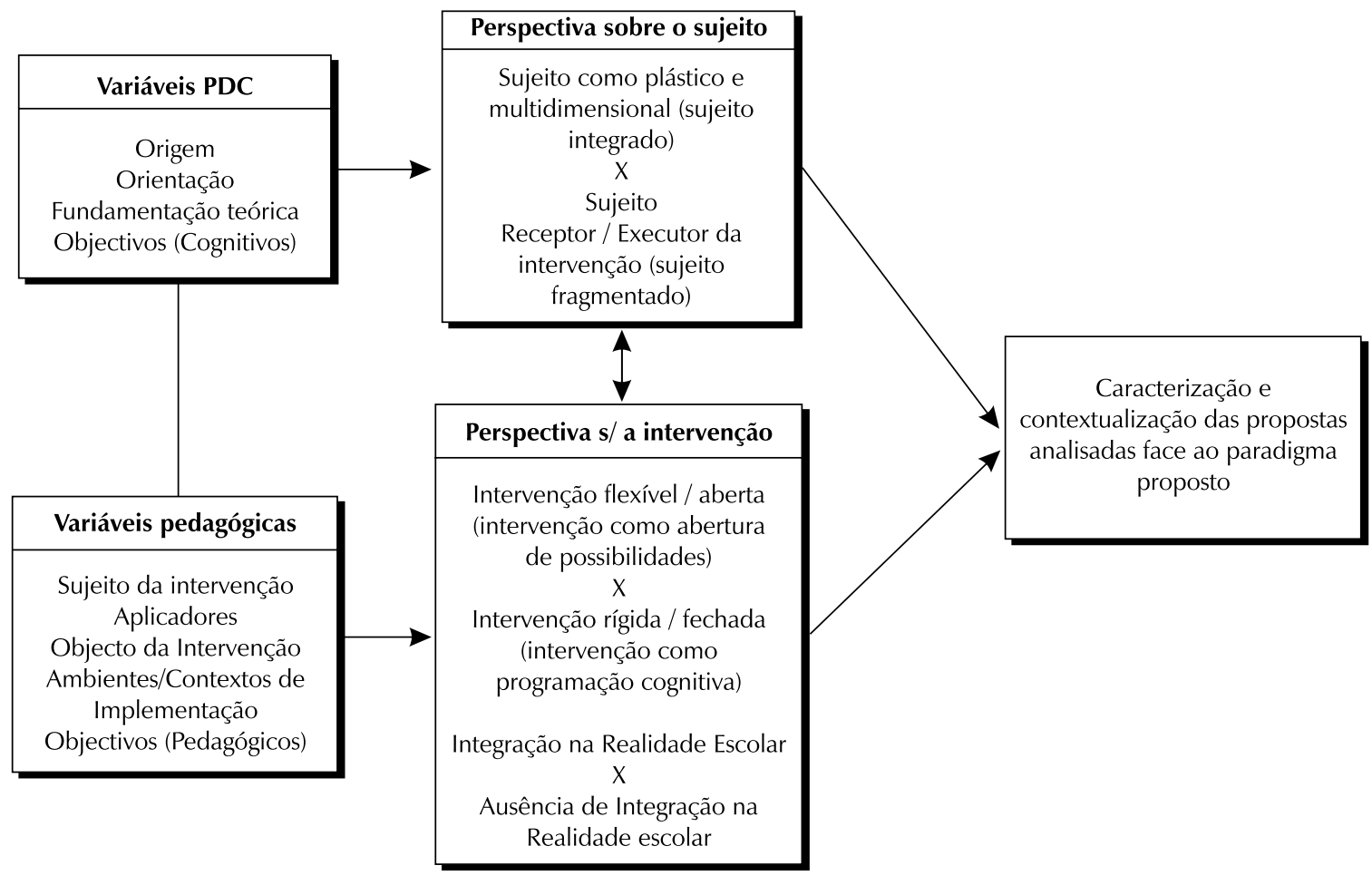

Quadro 1-Categorias e variáveis

\begin{tabular}{|c|c|}
\hline Variáveis & Categorias \\
\hline \multirow{2}{*}{ Origem } & Condições de emergência \\
\hline & Diagnóstico da situação \\
\hline \multirow{2}{*}{ Orientação } & Problemática interna \\
\hline & Intenções e objectivos gerais \\
\hline \multirow{5}{*}{ Fundamentação teórica } & Modelos teóricos \\
\hline & Conceitos-chave \\
\hline & Interdiscursividade \\
\hline & Perspectiva sobre as capacidades \\
\hline & Desenvolvimento e funcionamento mental \\
\hline \multirow{3}{*}{ Sujeito da intervenção } & Público-alvo \\
\hline & Características \\
\hline & Papel \\
\hline \multirow{3}{*}{ Formador/aplicador } & Papel \\
\hline & Condições de acesso \\
\hline & Formação específica no programa \\
\hline \multirow{7}{*}{ Objecto da intervenção } & Operacionalização \\
\hline & Efeitos pretendidos \\
\hline & Objectivos específicos das sessões \\
\hline & Modalidades de intervenção/actividades \\
\hline & Suportes materiais \\
\hline & Sequência/estrutura \\
\hline & Resultados/avaliações \\
\hline \multirow{3}{*}{ Ambientes/Contextos da intervenção } & Características \\
\hline & Relevância \\
\hline & Possibilidades de adaptação \\
\hline
\end{tabular}


Tereza N. R. Gonçalves

Promoção de habilidades cognitivas e educação: um modelo de análise de programas de desenvolvimento cognitivo

No âmbito educativo, a promoção do desenvolvimento cognitivo tem-se materializado em distintas propostas de intervenção conhecidas como programas de "ensinar a pensar" ou programas de desenvolvimento cognitivo (PDC). A partir da constatação da necessidade de uma aproximação crítica ao enquadramento conceptual e design dos referidos programas, o artigo apresenta um modelo de análise que parte do questionamento dos modelos teóricos que estão na base dos PDC. Propõe como referenciais teóricos da análise empreendida as teorias do desenvolvimento e da cognição emergentes das neurociências cognitivas e da biologia evolutiva, integradas no paradigma 
da complexidade, e elabora, com base nelas, um modelo de análise aplicado a um conjunto de programas seleccionados. O modelo proposto pode contribuir para repensar os programas existentes e propor novas formas de intervir neste campo em particular.

Palavras-chave: programas de desenvolvimento cognitivo; complexidade; modelos da cognição

Promotion of cognitive skills and education: a model of analysis of cognitive development programmes

In the educative environment, the promotion of cognitive development has materialized in distinct proposals of intervention known as programmes for "teaching how to think" or cognitive development programmes (CDP). Taking as a starting point the establishment of the need for a critical approach to the conceptual framing and design of such programmes, the article presents a model of analysis that starts by questioning the theoretical models that are at the base of the CDPs. It proposes as theoretical frameworks of the analysis undertaken, the theories of development and of cognition emerging from the cognitive neurosciences and from evolutionary biology, integrated in the paradigm of complexity and based on this, elaborates a model of analysis applied to a set of selected programmes. The proposed model can contribute to a rethinking of the existing programmes and to proposing new forms of intervention in this particular field.

Key words: cognitive development programmes; complexity; models of cognition

\section{La promoción de habilidades} cognitivas y educación: un modelo de análisis de programas de desarrollo cognitivo

En el ámbito educativo la promoción del desarrollo cognitivo se ha materializado en distintas propuestas de intervención conocidas como programas de "enseñar a pensar" $o$ programas de desarrollo cognitivo (PDC). La ausencia de un análisis crítico y de un cuestionamiento de los conceptos y teorías relacionados con la cognición y el desarrollo cognitivo en el ámbito de la promoción cognitiva, junto con la emergencia de nuevos modelos de la cognición y del desarrollo en diferentes áreas del saber, indicia la necesidad de una aproximación crítica al encuadramiento conceptual $y$ diseño de dichos programas. El modelo de análisis que se propone parte del cuestionamiento de los modelos teóricos que están en la base de los PDC, propone como referenciales teóricos del análisis emprendida las teorías del desarrollo y de la cognición emergentes en las neurociencias cognitivas y de la biología evolutiva, integrados en un paradigma de la complejidady elabora a partir de ellos un modelo de análisis que ha sido aplicado a un conjunto de programas seleccionados. El modelo propuesto puede contribuir para repensar los programas existentes y proponer nuevas formas de intervenir en este campo particular. Palabras clave: programas de desarrollo cognitivo, complejidad, modelos de la cognición 